\title{
Re-Tears after Surgically Treated Rotator Cuff Tears: What about the Clinical Outcome?
}

\author{
Enis Yildirim \\ Department of Orthopedics and Traumatology, \\ ALTINOVA Hospital, \\ Sakarya, Turkey \\ enisyldrm@hotmail.com \\ Gökhan Kaynak \\ Associate professor, Department of \\ Orthopedics and Traumatology, Cerrahpasa \\ Faculty of Medicine, \\ Istanbul University, Istanbul, Turkey \\ kaynak95@hotmail.com \\ Hayrettin Kesmezacar
}

Professor, Department of Orthopedics and

Traumatology, Cactus Health Center, Istanbul,

Turkey

hkesmezacar@yahoo.com
Egemen Ayhan

Department of Orthopedics and Traumatology, Mersin University Faculty of Medicine, Mersin, Turkey

egemenay@yahoo.com

Fatih Kantarci

Department of Radiodiagnostics, Cerrahpasa Faculty of Medicine,

Istanbul University, Istanbul, Turkey fatihkan@yahoo.com

\section{Muharrem Babacan}

Professor, Department of Orthopedics and Traumatology, Cerrahpasa Faculty of Medicine, Istanbul University, Istanbul, Turkey muharrem.babacan@istanbul.edu.tr

\begin{abstract}
:
Background: Rotator cuff tear is one of the most common sources of shoulder pain. Surgical indications for rotator cuff tear are one of the current topics for discussion. In this study, whether the integrity of the rotator cuff repair preserved was examined and the effects of re-tear on clinical outcome were assessed.
\end{abstract}

Methods: Patients whom were operated with open or mini-open rotator cuff repair technique were re-called. Clinical results were evaluated according to Constant-Murley and ASES scoring systems. Both shoulders of the patients were evaluated clinically. In addition, patients were examined by ultrasound for determining tendon integrity and with a analog dynamometer for muscle strength.

Results: The mean age of the 49 included patients (31 female, 18 male) was 55 (38-74). Mean follow-up time was 59 (12-119) months with a minimum of 18 months. Although, USG examination in 11 patients (22\%) revealed a re-tear, subjective satisfaction level was stated as excellent and good by \%94 of the patients. When integrity of the tendon and data were evaluated, older age and tear size were found as negative predictive factors for re-tear.

Conclusion: Although quite satisfactory medium-term functional outcomes were obtained with open and miniopen rotator cuff repairs, clinical results shown not to be parallel with the integrity of repair. Patient characteristics and tear properties should be considered while determining an indication for treatment of rotator cuff tears. Patients with advanced age and a large defect, should be informed for the risk of re-rupture to occur.

Keywords: Rotator cuff, integrity, ultrasonography, dynamometer, repair, open, mini-open, re-tear.

Abbreviations: BMI: body-mass index, ROM: range of motion, CM: Constant-Murley score

ASES: American Shoulder and Elbow Surgeons score,

VAS: Visual Analog Scale, NCSS®: Number Cruncher Statistical System,

PASS®: Power Analysis and Sample Size

USG: Ultrasonography, MRI: Magnetic Resonance Imaging 


\section{INTRODUCTION}

Rotator cuff tear is one of the major causes of shoulder pain. Advances in cuff surgery over the last decades have provided better shoulder function and satisfaction in patients with rotator cuff tears [19]. However, in a short to mid-term follow-up, several studies reported re-tears after surgically repaired rotator cuff tears $[2,4,10,11,13-18]$.

It is well-known that patient-related or biological factors affect the healing process of a repaired tendon $[11,12,19]$. But, the correlation of tendon integrity with clinical outcome is controversial throughout the current literature, and that causes difficulty while informing patient about the expected results after surgery $[4,6,14-16,21,22]$.

We hypothesized that, in surgically treated rotator cuff tears, some preoperative patient-related factors might give some clues for possible re-tears throughout a mid-term follow-up period and would affect the clinical outcome. Therefore, in surgically treated rotator cuff tears, this study was performed to find out; (1) the patient-related factors that might influence re-tear rate, (2) and the correlation between tendon integrity and functional outcome as well as patient satisfaction in a mid-term followup period.

\section{Materials AND Methods}

We retrospectively re-called 65 consecutive rotator cuff tear patients treated with open or mini-open technique by the same senior surgeon at a third step health-care center. Patients with partial to massive tears and with at least 18 months of follow-up were included in the study. Exclusion criteria were (1) refusal for the follow-up, (2) glenohumeral arthrosis, (3) bilateral operation, (4) previous surgery of the shoulder, (5) muscle weakness on upper extremity due to any neurovascular reason, (6) missing pre-operative or per-operative data. Three of patients were died of various reasons, 2 of them had been living abroad, 5 of them cannot be reached by given phone numbers or addresses and 6 of them refused the follow-up because of co-morbidities. After exclusions, 49 patients (31 men, 18 women) were enrolled into the study.

Informed consent was given by all patients, and permission was obtained from the local ethics committee. Age, occupation, cigarette use, diabetes mellitus existence, and body-mass index (BMI) were obtained from the patients' preoperative folders.

In the surgical technique, diagnostic glenohumeral arthroscopy was routinely done and if needed, arthroscopic subacromial decompression, bursectomy, and release of the coracohumeral ligament were performed. The rotator cuff tendon tear was repaired either with an open or a mini-open approach in regards to the tear size and senior surgeons' choice. A calibrated hook device was used to measure tear size. The tears were categorized as small (less than $1 \mathrm{~cm}$ in diameter), medium $(1-3 \mathrm{~cm}$ diameter), large (3-5 cm diameter), and massive (more than $5 \mathrm{~cm}$ diameter) according to DeOrio and Cofield classification system.

Postoperatively, a shoulder immobilizing sling with abduction pillow was prescribed to each patient. Gentle passive forward flexion was started on the postoperative day. Active assisted range of motion (ROM) exercises was started after the postoperative 4 to 6 weeks, depending on the patients' tolerance. Active resisted strengthening exercises were started 6 to 8 weeks after the operation. Patients were permitted to do daily light activities 2 to 3 months after surgery. Sports activities were allowed after postoperative 6 months.

Patients were called for last follow-up and grouped as "Intact" and "Re-tear' groups in regards to the ultrasonographic examination of rotator cuff tendon integrity by a senior musculoskeletal radiologist. The radiologist was blinded about the clinical results of the patients. GE LOGIQ E9 system (General Electrics, Inc., Connecticut, USA) with 5 and $10 \mathrm{Mhz}$. (megahertz) linear probes were used to examine the tendon integrity. Physical examination of the patients was performed by an orthopaedic surgeon who was not participated in the surgical procedure. ROM, muscle strength measured by an analog dynamometer (Baseline Evaluation Instruments, Fabrication Enterprises, Inc., New York, USA), satisfaction state, Constant-Murley (CM) score, ASES (American Shoulder and Elbow Surgeons) score, visual analog scale (VAS) for pain score were recorded. Higher VAS scores indicated a higher pain level. 


\section{Re-Tears after Surgically Treated Rotator Cuff Tears: What about the Clinical Outcome?}

The strength of the rotator cuff was tested with an analog dynamometer and patients were at upright standing position during the test. Analog dynamometer was fixed to a connection device on the wall. And the position of this connection device could be adjusted according to the tested muscle and height of the patient. Forward elevation was tested while the hand was at empty-can position, internal and external rotation was tested while the arm was adducted and elbow was fixed at $90^{\circ}$ flexion. Statistical analysis was performed using NCSS ${ }^{\circledR}$ (Number Cruncher Statistical System) version 2007 and PASS ${ }^{\circledR}$ (Power Analysis and Sample Size) version 2008 (NCSS, LLC, Utah, USA). Descriptive analysis of the demographic data was created as mean, standard deviation, median, frequency and percentages. Comparisons and correlations were made between 'Intact' and 'Re-tear' groups at last follow-up. Student $t$ test and Mann Whitney $U$ test were used for comparison of numerical data. Chi square and Fisher's exact test were used for comparison of qualitative data. Spearman's correlation analysis was used to determine the relationship between the parameters which were checked for correlation.

\section{RESUltS}

There were 38 patients in the 'Intact' group $(77,6 \%)$ and 11 patients $(22,4 \%)$ in the 'Re-tear' group. Re-tear rate of men was found as $19 \%$ and of women was found as $28 \%(\mathrm{p}=0.49)$. The mean age of the patients was 53.1 (range, 38-69) years for 'Intact' group and 60.8 (range, 44-74) years for 'Retear' group $(\mathrm{p}=0,002)$. The mean follow-up was 63.4 months for 'Intact' group and 43.8 months for 'Re-tear' group ( $\mathrm{p}=0,027)$. Demographic data of the groups are listed in table I.

Table1:

\begin{tabular}{|c|c|c|c|c|}
\hline & Intact group $(n=38)$ & Re-teargroup $(\mathrm{n}=11)$ & p value \\
\hline \multicolumn{2}{|l|}{ Age (year) } & 53,1 & 60,8 & 0,002 \\
\hline \multicolumn{2}{|c|}{ Follow-up time (month) } & 63,4 & 43,8 & 0,027 \\
\hline \multirow{3}{*}{ Occupation (n) } & Non-worker & $21(77,8 \%)$ & $6(22,2 \%)$ & \multirow{3}{*}{$1^{*}$} \\
\hline & Retired & $10(76,9 \%)$ & $3(23,1 \%)$ & \\
\hline & Worker & $7(77,8 \%)$ & $2(22,2 \%)$ & \\
\hline \multirow{3}{*}{ Cigarette use (n) } & Non-smoker & $23(82,1 \%)$ & $5(17,9 \%)$ & \multirow{3}{*}{$0,449 *$} \\
\hline & Smoker & $11(78,6 \%)$ & $3(21,4 \%)$ & \\
\hline & Quitted & $4(57,1 \%)$ & $3(42,9 \%)$ & \\
\hline \multirow{2}{*}{ Diabetes Mellitus (n) } & Yes & $5(71,4 \%)$ & $2(28,6 \%)$ & \multirow{2}{*}{$0,646^{+}$} \\
\hline & No & $33(78,6 \%)$ & $9(21,4 \%)$ & \\
\hline \multirow{2}{*}{ BMI (n) } & Normal $(<25)$ & $6(75 \%)$ & $2(25 \%)$ & \multirow{2}{*}{$0,85^{+}$} \\
\hline & Overweight $(25<)$ & $32(78 \%)$ & $9(22 \%)$ & \\
\hline
\end{tabular}

BMI, Body Mass Index; *, Fisher Freeman Halton test ${ }^{+}{ }^{+}$, Fisher's Exact test

Twelve of the patients were operated with the open technique and 37 were operated with mini-open. The mean per-operative tendon defect at coronal plane was $1,74 \pm 0,99 \mathrm{~cm}$. for 'Intact' group and $2,27 \pm 1,13 \mathrm{~cm}$. for 'Re-tear' group $(\mathrm{p}=0,072)$. There were 2 massive, 4 large, 22 medium and 21 small tears in this study. (Table II)

Table2:

\begin{tabular}{|c|c|c|c|c|c|}
\hline & \multicolumn{2}{|c|}{ Intact group } & \multicolumn{2}{|c|}{ Re-tear group } & \multirow[b]{2}{*}{ p value ${ }^{+}$} \\
\hline & $\mathbf{n}$ & $\%$ & $\mathrm{n}$ & $\%$ & \\
\hline Small & 16 & 84.2 & 3 & 15.8 & \multirow{4}{*}{0.146} \\
\hline Medium & 18 & 81.8 & 4 & 18.2 & \\
\hline Large & 3 & 60.0 & 2 & 40.0 & \\
\hline Massive & 1 & 33.3 & 2 & 66.7 & \\
\hline
\end{tabular}

+, Mann Whitney-U test

The mean abduction degree was significantly decreased $(\mathrm{p}=0.029)$ for "Intact" group $\left(158,16^{\circ} \pm\right.$ $\left.22,99^{\circ}\right)$ when compared with "Re-tear" group $\left(169,09^{\circ} \pm 5,39^{\circ}\right)$. Internal rotation level was significantly higher (interscapular) for "Intact" group $(\mathrm{n}=19)$ when compared with "Re-tear" group $(n=0)$. Otherwise, there was no significant difference between two groups by means of ROM (Table III). The muscle strength calculated with dynamometer was not significantly different between groups for forward elevation, external rotation, and internal rotation (Table IV). 
Enis Yildirim et al.

Table3:

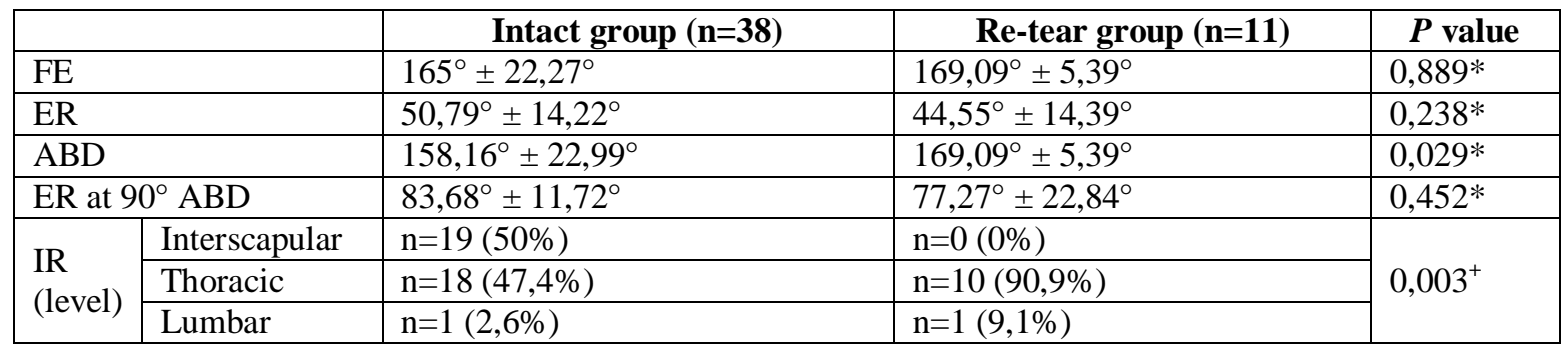

ROM, Range of motion; USG, Ultrasonography; SD, Standard deviation; *, Chi-square test; FE, Forward elevation; ER, External rotation; ABD, Abduction; IR, Internal rotation; USG, Ultrasonography; ${ }^{+}$, Mann Whitney-U test

Table4:

\begin{tabular}{|l|l|l|l|}
\hline & \multicolumn{1}{|c|}{$\begin{array}{c}\text { Intact group (kg.) } \\
\text { Mean } \pm \text { SD (median) }\end{array}$} & \multicolumn{1}{|c|}{$\begin{array}{c}\text { Re-tear group (kg.) } \\
\text { Mean } \pm \text { SD (median) }\end{array}$} & $\boldsymbol{P}_{\text {value }}^{+}$ \\
\hline FE & $5,87 \pm 2,07(6)$ & $4,77 \pm 1,98(4,5)$ & 0,126 \\
\hline ER & $6,64 \pm 2,19(6)$ & $6,27 \pm 2,42(5)$ & 0,432 \\
\hline IR & $5,2 \pm 1,51(5)$ & $4,77 \pm 1,65(5)$ & 0,371 \\
\hline
\end{tabular}

USG, Ultrasonography; SD, Standard deviation; ${ }^{+}$, Mann Whitney-U test; FE, Forward elevation; ER, External rotation; IR, Internal rotation.

Mean VAS score was $0,37 \pm 1,32$ in intact group and 1,00 $\pm 1,67$ in re-tear group $(\mathrm{p}=0,029)$. Mean CM scores of the intact group was 80,1 and of re-tear group was 74,1 at last follow-up ( $\mathrm{p}=0,143)$. Mean ASES scores of the intact group was 94,6 and of re-tear group was 87,4 at last follow-up $(p=0,197)$. And as the follow-up time increases, CM $(p=0,036)$ and ASES $(p=0,009)$ scores deteriorates with time in the re-tear group but these scores get better in the intact group with increasing follow-up period (Figure 1 and 2).

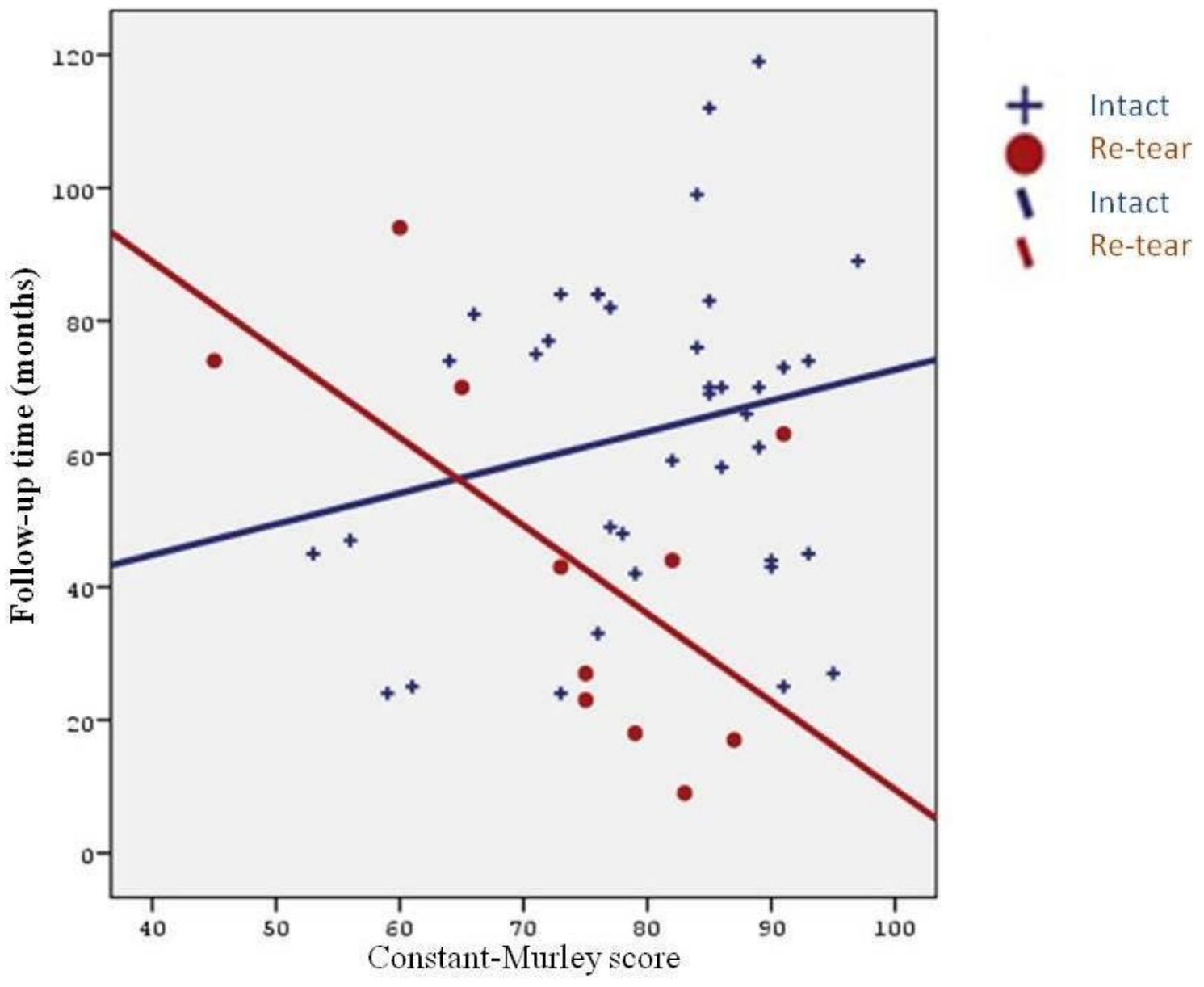

Figure1: CM score deterioration in re-tear group 


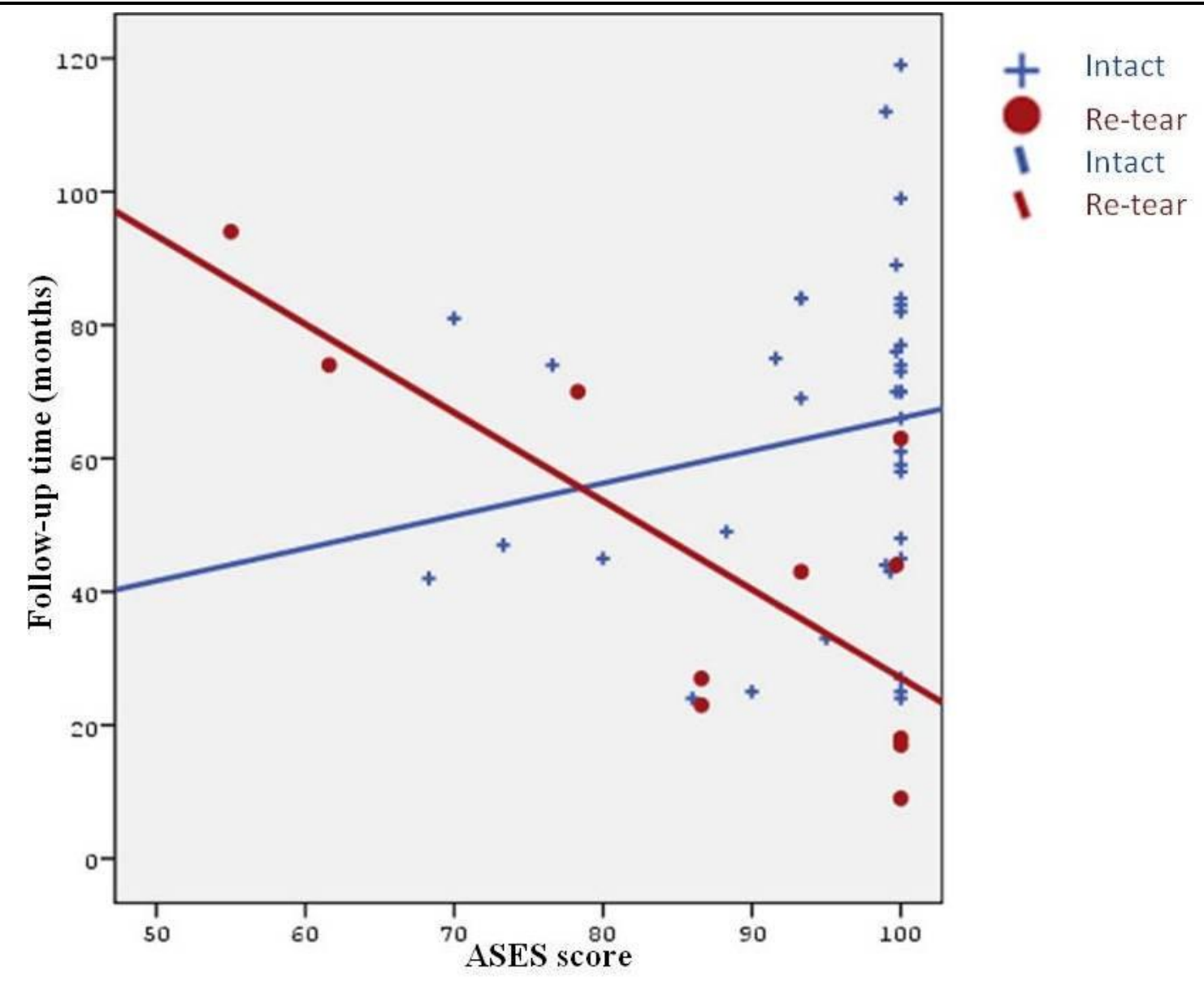

Figure2: ASES score deterioration in re-tear group

Subjective satisfaction level was stated as 'satisfied' by $94,7 \%(\mathrm{n}=36)$ of intact group and $\% 91(\mathrm{n}=10)$ of re-tear group was stated as 'satisfied'.

\section{DisCUSSION}

Rotator cuff tears are one of the most commonly diagnosed orthopedic problems of the upper extremity. Prevalence of rotator cuff tears is age-related, and is thought to be more than $50 \%$ of patients over 60 years of age [22]. Recent developments in shoulder surgery aim to have better shoulder function and less pain after treatment of patients with rotator cuff tear. Although the studies, which had been done on the security of the repair techniques, led to the development of repair; recent evidence directs our attention towards biology [19]. In a recently reported review by Mall et al, only age, fatty infiltration and tear size were found to be a predictor and authors found that outcome scores were affected by tendon status but patient perceived outcomes were not [12]. Currently there are questions about predictive factors for a re-tear and what if a re-tear occurs. So, it becomes difficult to inform a patient about the expected results after surgery. Therefore, this study evaluates the preoperative demographic data and peroperative factors that may influence tendon integrity and correlation between tendon integrity and clinical outcome for mini-open or open repair of rotator cuff tears in a mid-term follow-up period.

Lack of dynamometer values of pre-operative muscle strength, lack of preoperative ASES scores, different surgical techniques, low percentage of included patients $(75 \%)$ and third-step health care unit bias were limitations of this study.

Among the demographic data and peroperative factors, only age was found to be a predictor of tendon integrity $(\mathrm{p}=0,002)$. Also mean per-operative tendon defect at coronal plane was smaller for intact group but statistical power of this data was weak $(\mathrm{p}=0,072)$. There are high number of reports in the literature which agreed in the idea that age and defect size are the most consistent two independent factors for rotator cuff integrity [6, 13, 25, 39, 45, 46]. Although, in the literature cigarette smoking $[47,48]$ was found to be a predictor of tendon integrity, probably depending on the small number of our cohort, we were not able to find any relation. 
The re-tear rates after open, "mini-open" and arthroscopic repair have improved during recent decades, as demonstrated by arthrography [23,24], ultrasonography $[13,25]$ and magnetic resonance imaging (MRI) [26-29]. USG was used to evaluate the tendon integrity at last control in this study. As mentioned in the literature, however it's a user dependent technique, USG is a superior method for postoperative imaging of the shoulder when done by an experienced musculoskeletal radiologist [30] and also it has greater specifity compared to other imaging modalities [30,31].

In current study re-tear rate was found as $22,4 \%(n=11)$ on USG examination at last control. Re-tear rate of this study compares parallelly with the rates of $20-60 \%$ that were reported in the literature for open or mini-open rotator cuff repairs [6,10,13,19-21,23,25,32-35]. Relatively lower re-tear rate that was found in this study may be attributable to relatively smaller mean defect size $(1,86 \mathrm{~cm}$.) and relatively younger patient population (Mean age - 55 years). There are many reports which demonstrated that chronic and massive tears have a high re-tear rate after open or arthroscopic repairs $[4-6,13,14,20,34,36-43]$. Re-tear was seen at 17 of 18 tendons by ultrasound in a study with a minimum follow-up of 12 months [25]. In a prospective study, the overall re-tear rate was found as $40 \%$ [29]. After open repair, tendon integrity was to be found as $60 \%$ for two-tendon tears in a report [13] and in another study that was done after open repair, it was found that two-tendon tears were intact in 50\% and three-tendon tears in 33\% [6]. After repair of tears smaller than $3 \mathrm{~cm}$, open and arthroscopic RCR provided satisfactory clinical results, with a high rate (74\% for open, $84 \%$ for arthroscopic) of rotator cuff integrity after a minimum follow-up of 1 year [38].

The effects of tendon integrity on clinical outcome after rotator cuff repair had been researched in the literature over recent years. Although a positive effect of tendon integrity on clinical outcome was found in many of them $[4,6,14,15,20,49]$, some of those studies reported a weak correlation between tendon integrity and clinical outcome after repair of medium and large tears $[13,20,21]$. Many reporters found that muscle strength and mean abduction degree were higher for intact groups. $[6,33,34,39]$ In the current study, subjective satisfaction level was not seemed to be affected by tendon status. When the correlation between the tendon integrity and clinical results was checked, only internal rotation active ROM and VAS were seemed to be better in intact group. Lower mean abduction degree for "Intact" group and relatively small difference of muscle strength between two groups were unexpected results in this study. We thought that this result may be attributable to the longer mean follow-up time of "Intact" group.

Effects of tendon integrity on functional outcome have been asked throughout the literature. Correlation between integrity and functional outcome was not found in a report which was evaluated tendon integrity with MRI after single tendon tear repair of 31 patients and found a re-tear rate of $32 \%$ [21]. A recent study with 9,9 years mean follow-up time was revealed that patients were satisfied with the results after open repair of massive tears despite the high re-tear rate (57\%) [43]. That study group was also evaluated those patients at 3,2 years follow-up and they stated that re-tear rate increases with time but subjective satisfaction level remains almost same [43]. In a prospective study of 32 open repairs, re-tear rate was found to be as $31 \%$ after minimum 1 year follow-up but clinical outcome was not seemed to be affected by integrity [41]. When the CM and ASES scores of the intact and re-tear group were compared, scores of re-tear group seems to be lower but a statistical difference did not exist in our cohort. And as the follow-up time increases, CM and ASES scores deteriorates with time in the re-tear group. This finding was supported by the results of a report which found $94 \%$ re-tear rate and deterioration of ASES score with longer follow-up time [25].

\section{CONCluSion}

When the current study and literature evaluated, it should be thought that open and mini-open repair of rotator cuff tears have satisfactory mid-term functional results but clinical outcome does not seem to correlate with tendon integrity. As the tear size and age were found to be most important two factors on tendon integrity, older patients and patients with high defect size should be informed about re-tear possibility and what if a re-tear occurs.

\section{REFERENCES}

[1] Baker CL, Liu SH. Comparison of open and arthroscopically assisted rotator cuff repairs. Am J Sports Med 1995; 23:99-104.

[2] Cofield RH, Parvizi J, Hoffmeyer PJ, Lanzer WL, Ilstrup DM, Rowland CM. Surgical repair of chronic rotator cuff tears. A prospective long-term study. J Bone Joint Surg Am 2001; 83:71-7. 
[3] Davidson PA, Rivenburgh DW. Rotator cuff repair tension as a determinant of functional outcome. J Shoulder Elbow Surg 2000; 9:502-6.

[4] Fuchs B, Gilbart MK, Hodler J, Gerber C. Clinical and structural results of open repair of an isolated one-tendon tear of the rotator cuff. J Bone Joint Surg Am 2006; 88:309-16.

[5] Galatz LM, Griggs S, Cameron BD, Iannotti JP. Prospective longitudinal analysis of postoperative shoulder function: a ten-year follow-up study of full-thickness rotator cuff tears. $\mathrm{J}$ Bone Joint Surg Am 2001; 83:1052-6.

[6] Harryman DT, Mack LA, Wang KY, Jackins SE, Richardson ML, Matsen FA III. Repairs of the rotator cuff: correlation of functional results with integrity of the cuff. J Bone Joint Surg Am 1991; 73:982-9.

[7] Romeo AA, Hang DW, Bach BR Jr, Shott S. Repair of full thickness rotator cuff tears. Gender, age, and other factors affecting outcome.Clin Orthop Relat Res 1999:243-55.

[8] Sperling JW, Cofield RH, Schleck C. Rotator cuff repair in patients fifty years of age and younger. J Bone Joint Surg Am 2001; 83:1052-6.

[9] Williams GR Jr, Rockwood CA Jr, Bigliani LU, Iannotti JP, Stanwood W. Rotator cuff tears: why do we repair them? J Bone Joint Surg Am 2004; 86:2764-76.

[10] Calvert PT, Packer NP, Stoker DJ, Bayley JI, Kessel L. Arthrography of the shoulder after operative repair of the torn rotator cuff. J Bone Joint Surg Br. 1986; 68:147-150.

[11] Ellman H, Hanker G, Bayer M. Repair of the rotator cuff: end result study of factors influencing reconstruction. J Bone Joint Surg Am. 1986; 68:1136-44.

[12] Mall NA, Tanaka MJ, Choi LS, Paletta GA. Factors Affecting Rotator Cuff Healing. J Bone Joint Surg Am. 2014; 96:778-88. doi: 10.2016/JBJS.M.00583

[13] Gazielly DF, Gleyze P, Montagnon C. Functional and anatomical results after rotator cuff repair. Clin Orthop Relat Res.1994; 304:43-53.

[14] Gerber C, Fuchs B, Hodler J. The results of repair of massive tears of the rotator cuff. J Bone Joint Surg Am. 2000; 82:505-15.

[15] Goutallier D, Postel JM, Bernageau J, Lavau L, Voisin MC. Fatty muscle degeneration in cuff ruptures: pre- and postoperative evaluation by CT scan. Clin Orthop Relat Res. 1994;304:78-83.

[16] Hawkins RJ, Misamore GW, Hobeika PE. Surgery for full thickness rotator-cuff tears. J Bone Joint Surg Am. 1985; 67:1349-55.

[17] Thomazeau H, Boukobza E, Morcet N, Chaperon J, Langlais F. Prediction of rotator cuff repair results by magnetic resonance imaging. Clin Orthop Relat Res. 1997; 344:275-83.

[18] Zilber S, Carillon Y, Lapner PC, Walch G, Nove'-Josserand L. Infraspinatus delamination does not affect supraspinatus tear repair. Clin Orthop Relat Res. 2007; 458:63-9.

[19] Papadopoulos P, Karataglis D, Boutsiadis A, Fotiadou A, Christoforidis J, Christodoulou A. Functional outcome and structural integrity following mini-open repair of large and massive rotator cuff tears: a 3-5 year follow-up study. J Shoulder Elbow Surg 2011;20(1):131-7.

[20] Jost B, Pfirrmann CW, Gerber C. Clinical outcome after structural failure of rotator cuff repairs. J Bone Joint Surg [Am] 2000;82:304-14.

[21] Knudsen HB, Gelineck J, Sojbjerg JO, Olsen BS, Johannsen HV, Sneppen O. Functional and magnetic resonance imaging evaluation after single-tendon rotator cuff reconstruction. $\mathrm{J}$ Shoulder Elbow Surg 1999; 8:242-6.

[22] Sher JS, Uribe JW, Posada A, Murphy BJ, Zlatkin MB. Abnormal findings on magnetic resonance images of asymptomatic shoulders. J Bone Joint Surg [Am] 1995; 77:10-5.

[23] Liu SH, Baker CL. Arthroscopically assisted rotator cuff repair: correlation of functional results with integrity of the cuff. Arthroscopy. 1994; 10:54-60.

[24] Worland RL, Arredondo J, Angles F, Lopez-Jimenez F. Repair of massive rotator cuff tear in patients older than 70 years. J Shoulder Elbow Surg. 1999; 8:26-30.

[25] Galatz LM, Ball CM, Teefey SA, Middleton WD, Yamaguchi K. The outcome and repair integrity of completely arthroscopically repaired large and massive rotator cuff tears. J Bone Joint Surg Am. 2004; 86-A: 219-24.

[26] Frank JB, ElAttrache NS, Dines JS, Blackburn A, Crues J, Tibone JE. Repair site integrity after arthroscopic transosseous-equivalent suture-bridge rotator cuff repair. Am J Sports Med. 2008; 36:1496-503. 
[27] Gaenslen ES, Satterlee CC, Hinson GW. Magnetic resonance imaging for evaluation of failed repairs of the rotator cuff. J Bone Joint Surg Am. 1996; 78:1391-6.

[28] Motamedi AR, Urrea LH, Hancock RE, Hawkins RJ, Ho C. Accuracy of magnetic resonance imaging in determining the presence and size of recurrent rotator cuff tears. J Shoulder ElbowSurg. 2002; 11:6-10.

[29] Sugaya H, Maeda K, Matsuki K, Moriishi J. Repair integrity and functional outcome after arthroscopic double-row rotator cuff repair. A prospective study. J Bone Joint Surg. 2007; 89:953-60.

[30] Teefey SA, Hasan SA, Middleton WD, Patel M, Wright RW, Yamaguchi K Ultrasonography of the rotator cuff. A comparison of ultrasonographic and arthroscopic findings in one hundred consecutive cases. J Bone Joint Surg [Am] 2000; 82:498-504.

[31] Prickett WD, Galatz LM, Calfee R, Teefey S, Middleton WD, Yamaguchi K. The accuracy of ultrasound for imaging the rotator cuff in the postoperative shoulder. Read at the Annual Meeting of the American Academy of Orthopaedic Surgeons; San Francisco, CA: Feb 28-Mar 4, 2001.

[32] Hanusch BC, Goodchild L, Finn P, Rangan A. Large and massive tears of the rotator cuff: functional outcome and integrity of the repair after a mini-open procedure. J Bone Joint Surg $\mathrm{Br}$ 2009; 91:201-5.

[33] Lafosse L, Brozska R, Toussaint B, Gobezie R. The outcome and structural integrity of arthroscopic rotator cuff repair with use of the double-row suture anchor technique. J Bone Joint Surg (Am) 2007; 89:1533-41.

[34] Cho NS, Rhee YG. The factors affecting the clinical outcome and integrity of arthroscopically repaired rotator cuff tears of the shoulder. Clin Orthop Surg 2009; 1(2):96-104.

[35] Tashjian RZ, Hollins AM, Kim HM, Teefey SA, Middleton WD, Steger-May K, et al: Factors affecting healing rates after arthroscopic double-row rotator cuff repair. Am J Sports Med 2010; 38(12):2435-42.

[36] Bartl C, Kouloumentas P, Holzapfel K, Eichhorn S, Wörtler K, Imhoff A, et al. Long-term outcome and structural integrity following open repair of massive rotator cuff tears. Int $\mathbf{J}$ Shoulder Surg. 2012; 6:1-8.

[37] Bartl C, Senftl M, Eichhorn S, Holzapfel K, Imhoff A, Salzmann G. Combined tears of the subscapularis and supraspinatus tendon: clinical outcome, rotator cuff strength and structural integrity following open repair. Arch Orthop Trauma Surg. 2012; 132: 41-50.

[38] Bishop J, Klepps S, Lo IK, Bird J, Gladstone JN, Flatow EL. Cuff integrity after arthroscopic versus open rotator cuff repair: a prospective study. J Shoulder Elbow Surg. 2006;15:290-9.

[39] Cole BJ, McCarty LP 3rd, Kang RW, Alford W, Lewis PB, Hayden JK. Arthroscopic rotator cuff repair: prospective functional outcome and repair integrity at minimum 2-year follow-up. J Shoulder Elbow Surg. 2007;16:579-85.

[40] Gulotta LV, Nho SJ, Dodson CC, Adler RS, Altchek DW, MacGillivray JD; HSS Arthroscopic Rotator Cuff Registry. Prospective evaluation of arthroscopic rotator cuff repairs at 5 years: Part II. Prognostic factors for clinical and radiographic outcomes. J Shoulder Elbow Surg. 2011; 20:941-6.

[41] Klepps S, Bishop J, Lin J, Cahlon O, Strauss A, Hayes P, et al. Prospective evaluation of the effect of rotator cuff integrity on the outcome of open rotator cuff repairs. Am J Sports Med.2004; 32:1716-22.

[42] Koh KH, Laddha MS, Lim TK, Park JH, Yoo JC. Serial structural and functional assessments of rotator cuff repairs: do they differ at 6 and 19 months postoperatively? J Shoulder Elbow Surg. 2012; 21: 859-66.

[43] Zumstein MA, Jost B, Hempel J, Hodler J, Gerber C. The clinical and structural long-term results of open repair of massive tears of the rotator cuff. J Bone Joint Surg Am. 2008;90:242331

[44] Wu XL, Briggs L, Murrell GA. Intraoperative determinants of rotator cuff repair integrity: an analysis of 500 consecutive repairs. Am J Sports Med. 2012 Dec; 40(12):2771-6. doi: $10.1177 / 0363546512462677$. 
[45] Boileau P, Brassart N, Watkinson DJ, Carles M, Hatzidakis AM, Krishnan SG: Arthroscopic repair of full-thickness tears of the supraspinatus: Does the tendon really heal? J Bone Joint Surg [Am] 2005; 87:1229-40.

[46] Nho SJ, Brown BS, Lyman S, Adler RS, Altchek DW, MacGillivray JD. Prospective analysis of arthroscopic rotator cuff repair: Prognostic factors affecting clinical and ultrasound outcome. J Shoulder Elbow Surg. 2009; 18:13-20.

[47] Carbone S, Gumina S, Arceri V, Campagna V, Fagnani C, Postacchini F. The impact of preoperative smoking habit on rotator cuff tear: cigarette smoking influences rotator cuff tear sizes. J Shoulder Elbow Surg. 2012;21(1):56-60.

[48] Baumgarten KM, Gerlach D, Galatz LM, Teefey SA, Middleton WD, Ditsios K, et al. Cigarette smoking increases the risk for rotator cuff tears. Clin Orthop Relat Res. 2010;468(6):1534-41.

[49] Goutallier D, Postel JM, Gleyze P, Leguilloux P, Van Driessche S. Influence of cuff muscle fatty degeneration on anatomic and functional outcomes after simple suture of full-thickness tears. $\mathbf{J}$ Shoulder Elbow Surg. 2003; 12:550-4. 